\title{
BERYLLIUM DESORPTION FROM MINERALS AND ORGANIC LIGANDS OVER TIME
}

\author{
Vanessa Boschi $^{1^{*}}$ and Jane K. Willenbring ${ }^{1}$ \\ ${ }^{1}$ Department of Earth and Environmental Science, University of Pennsylvania, \\ 251 Hayden Hall, 240 South 33rd Street, Philadelphia, Pennsylvania, 19104, USA
}

*vaboschi@ sas.upenn.edu; P: (610)-209-6119, F: (215) 898-0964

Abstract:

Beryllium isotopes sorbed to sediments have provided useful tools in the field of geochronology and geomorphology over the last few decades. The use of beryllium isotopes relies on the premise that beryllium sorbed to sediments is unaltered over large timescales. Changes in the environmental chemistry, either in-situ or en route from soil to fluvial system, to the ocean, can cause beryllium desorption and may preclude some beryllium isotopic applications.

Four mechanisms were tested to determine the relative desorption potential of beryllium including a reduction in $\mathrm{pH}$, an increase in ionic strength $(\mathrm{NaCl})$ and complexation by soluble organic (malonic acid) and inorganic species $(\mathrm{NaF})$. To assess the relative effect of each mechanism on beryllium desorption from both organic and mineral fractions, we prepared separate solutions of beryllium bound to minerals and organic compounds and measured beryllium concentrations in solution before and after each chemical perturbation. We conclude a reduction in $\mathrm{pH}$ resulted in the greatest amount of desorption among the four treatments, removing $97 \%$ and $75 \%$ of sorbed beryllium from illite and montmorillonite, respectively, and none from the organic ligands tested. The addition of malonic acid also resulted in desorption only from montmorillonite. Although increasing the ionic strength did remove $32 \%$ and $8.4 \%$ of beryllium from montmorillonite and sulfonate, respectively, the presence of sodium significantly 
enhanced sorption to illite. The addition of $\mathrm{NaF}$ did not result in beryllium desorption. Our results demonstrate that various chemical processes can promote the exchange of beryllium between solid and dissolved phases, the extent to which depends on the composition of the system.

We also related differences in beryllium desorption behavior to complexation mechanisms driving retention among organic and mineral species. We estimate inner sphere complexation dominates beryllium sorption by the organic ligands tested due to the minimal amounts of desorption. Because beryllium sorption was reversible due to changes in $\mathrm{pH}$, ionic strength and organic acid complexation, we hypothesize that outer sphere processes, driven by weaker electrostatic attractions, govern beryllium-montmorillonite associations. Beryllium exhibited a unique relationship with illite in that sorption appears to be dominated by not only inner sphere processes but also physical inclusion within collapsed interlayer spaces. Keywords:

beryllium; desorption; minerals; organic ligands; inner and outer sphere complexation

\section{$1 \quad$ Introduction}

In the past few decades, beryllium isotopes have been used in the field of geomorphology and geochronology to determine the residence time of sediments in landscapes ranging from several weeks to millions of years (Granger et al, 2013; Wallbrink and Murray, 1996; Willenbring and von Blanckenburg, 2010a and 2010b). These methods use concentrations of beryllium isotopes sorbed to sediments and often rely on the assumption that these concentrations are unchanged over such large timescales. However various biotic and abiotic processes could influence beryllium's behavior in soils and aquatic environments. As sediment is transported, undergoing various cycles of erosion and deposition, beryllium sorbed to these 
particles is exposed to a variety of different chemical environments and is susceptible to transformations along the path from source to sink. For example, marine core sediments used to measure ${ }^{10} \mathrm{Be} /{ }^{9} \mathrm{Be}$ ratios for estimating total denudation in a landscape can experience a salinity gradient during their transport from fresh to saline waters. Such changes in the ionic strength could result in competition for sorption sites and subsequent desorption of beryllium.

Additionally, within a single soil profile, in-situ processes like plant and microbial production of chelating organic acids can stimulate beryllium mobilization altering its natural distribution with depth. Beryllium desorption poses a problem for the environmental scientist and the geomorphologist, both of whom rely on the retention of beryllium to sediment to prevent the contamination of ground water, preserve a landscape's erosional signature and for tracking particle movement. Therefore, although the sorption behavior of beryllium is important to understand, it is equally important to consider processes that cause desorption.

In this study, we investigate four major processes known to stimulate metal desorption including a reduction in $\mathrm{pH}$, an increase in the ionic strength and complexation by soluble organic and inorganic species. A decrease in $\mathrm{pH}$ reduces available sorption sites encouraging the exchange of sorbed cations for protons. Increasing the ionic strength also enhances competition between cations for reactive sites on the surfaces of particles, resulting in desorption of ions previously bound to the surface. Additionally, low molecular weight organic acids (LMWOA) that are excreted by biota are capable of chelating cationic species like beryllium, mobilizing them into the soil solution (Qin, et al, 2004; Vanhees et al, 1999; Vranova et al, 2013).

Examples of such acids include oxalic, malonic, succinic and other dicarboxylic acids. In addition to organic ligands, beryllium is also complexed by inorganic species such as fluoride. Previous studies determined that dissolved, unsorbed beryllium concentrations were dependent 
on the amount of fluoride in fresh water systems and that the presence of fluoride can increase the mobility of beryllium (Vesely et al, 1989; Vesely et al, 2002; Kram et al, 1998).

Although these chemical perturbations are intended to provide us with a greater understanding of processes driving beryllium desorption, the rate and extent of desorption can also provide information relating to the predominant complexation mechanism among the organic ligands and mineral tested. Sorption processes can be characterized as specific and nonspecific. Non-specific sorption, or outer sphere complexation, involves the electrostatic interactions of hydrated metal ions with sorption sites. Considering these interactions are driven simply by differences in charge, there is less specificity among ligand type. Conversely, specific sorption, also referred to as inner sphere complexation, involves an actual chemical reaction between the metal and sorption site. The term 'specific' refers to the thermodynamic preference of a metal ion to form a covalent bond with particular ligands. Considering specific, inner sphere complexation involves the formation of chemical bonds, it produces a stronger metal-ligand association compared to outer sphere complexation. These inner sphere complexation mechanisms are therefore more resistant to chemical disturbances affecting the electrostatic interactions between metal and ligand like changes in ionic strength or $\mathrm{pH}$. Typically, $\mathrm{x}-\mathrm{ray}$ absorbance spectroscopy is used to assess the dominate complexation mechanism driving metals retention among sorbents. However, beryllium's transparency to x-rays complicates the use of such techniques. Therefore, the use of desorption experiments to assess the ease of beryllium removal from organic and mineral sorbents can be used to estimate dominant sorption types, with outer sphere complexation allowing for greater desorption at faster rates. We can use this knowledge to estimate how beryllium chemically associates with specific organic ligands and minerals. 
101 sorbed and dissolved phases is central in understanding not only the potential for beryllium

102 desorption and mobilization but the predominant complexation mechanism among organic and

103 mineral sorbents. The goals of this paper are to 1) establish the relative effect of each chemical

104 perturbation on beryllium desorption, 2) to determine the relative strength of beryllium

105 desorption from organic ligands versus mineral sorbents and 3) to indirectly estimate the

106 predominant sorption mechanism by observing their responses and determine how those

107 mechanisms may differ among organic ligands and minerals.

108

109

110

111

112

113

114

115

116

117

118

119

120

121

122

123

\section{Materials and Methods}

\subsection{Sorption of Beryllium to Sorbent Materials}

In order to test the ability of different processes to desorb beryllium, we initially needed to sorb beryllium to organic and inorganic sorbents. We selected two clay minerals to represent the mineral fraction and two organic compounds to represent the organic matter fraction of soils. We chose to use standard, model materials in order to identify how different chemical perturbations individually affect the retention of beryllium by either mineral or organic fractions. By observing their behavior separately we are able to better approximate the extent each chemical perturbation has on a natural soil depending on its organic or clay mineral content. Using model materials also removes any uncertainty that results from the complex and heterogeneous nature of using an actual soil sample and can allow us to better elucidate differences in the desorption behavior of beryllium between organic and inorganic soil materials. We selected mineral and organic materials based on their ability to complex beryllium as determined from previous experiments (Boschi and Willenbring, 2016). Of the minerals tested, 
124 illite and montmorillonite exhibited the greatest amount of beryllium sorption. We obtained

125 these minerals through Ward science (Rochester, NY, USA) and confirmed their mineralogical

126 purity using $\mathrm{x}$-ray diffraction (XRD). The samples were ground using a disc mill and rinsed with

127 a weakly acidic $\mathrm{HCl}$ (Fisher Scientific, Pittsburgh, PA, USA) solution and ultrapure Millipore

128 (Billerica, MA, USA) water to remove impurities. The minerals were then wet sieved and dried

129 in an oven overnight. The $<20 \mu \mathrm{m}$ fraction was collected for use in this experiment. A

130 Beckman-Coulter Particle Size Analyzer (Miami, FL, USA) was used to determine the

131 proportion of each mineral sample that was smaller than $0.45 \mu \mathrm{m}$ to ensure the filter removed

132 mineral particles from solution. It was determined that less than $0.5 \%$ of the sample was smaller

133 than $0.45 \mu \mathrm{m}$. As an additional precaution in order to ensure particles were not escaping through

134 the filter, all mineral samples were centrifuged at the appropriate speed and time interval prior to

135 filtration to ensure the $>99.5 \%$ of particles were excluded from the filtrate.

136 Similarly to the mineral samples, we selected phosphonic and sulfonic acid bearing

137 compounds because they formed the most stable complexes with beryllium relative to other

138 organic compounds tested in previous experiments (Boschi and Willenbring, 2016).

139 Octadecylphosphonic acid (Sigma Aldrich, St. Louis, MO, USA), a large insoluble alkane and

140 toluenesulfonic acid bound to a polystyrene resin (30-60 mesh size) (Alfa Aesar, Ward Hill, MA,

141 USA) were selected to represent a phosphonate and sulfonate group respectively. These

142 compounds were selected so that they could be easily separated from solution by filtration using

143 a $0.45 \mu \mathrm{m}$ filter. By selecting organic ligands and minerals with larger stability constants

144 relative to other materials, our results will provide a conservative estimate of beryllium

145 desorption from ligands physically available to do chemistry in natural environments. 
For each mineral or organic material, we prepared 72 beryllium-sorbent solutions, which allowed a sufficient number for triplicate analysis at 6 different time intervals for each of the four chemical treatments. We prepared an additional 21 beryllium-sorbent solutions for each sorbent material to function as controls. These 21 solutions (three designated for each time interval plus an additional three for time ' 0 ' to determine the initial amount of sorbed beryllium) would not be perturbed by any of the chemical amendments and would act to monitor the amount of beryllium in solution over the entire duration of the experiment. Following each chemical treatment, we compared beryllium concentrations in solution to the concentration of beryllium in the control sample at the same time interval. The six time intervals included 1 hour, 3 hours, 6 hours, 12 hours, 1 day and 7 days. Therefore we made a total of 372 solutions.

We prepared individual organic compounds and mineral solutions at a concentration of $250 \mathrm{mg} \mathrm{L}^{-1}$. It is important to note that for organic compounds $250 \mathrm{mg} \mathrm{L}^{-1}$ represents the concentration of the active functional group, not the entire organic molecule because the ratio of functional group to organic compound mass varies from compound to compound. For example, $250 \mathrm{mg} \mathrm{L}^{-1}$ phosphonate $\left(\mathrm{PO}_{3}\right)$ was prepared rather than $250 \mathrm{mg} \mathrm{L}^{-1}$ of octadecylphosphonic acid $\left(\mathrm{C}_{18} \mathrm{H}_{39} \mathrm{O}_{3} \mathrm{P}\right)$. However, for the mineral samples, $250 \mathrm{mg} \mathrm{L}^{-1}$ represents the concentration of the bulk mineral. We used a beryllium concentration of $1 \mathrm{mg} \mathrm{L}^{-1}$ to mimic its average abundance in natural soils and to ensure its instrumental detection (Taylor et al, 2003; USDHHS, 2002). We prepared our beryllium stock solution using a beryllium ICP standard (BDH, Lutterworth, UK). The solutions were prepared in ultrapure Millipore water and initially adjusted to a $\mathrm{pH}$ of 6 to ensure maximum sorption. We could not exceed a $\mathrm{pH}$ of 6 considering the dependence of beryllium speciation on $\mathrm{pH}$. At a concentration of $1 \mathrm{mg} \mathrm{L}^{-1}$, beryllium is present as a divalent cation at low $(<6.5)$ and high $(>11) \mathrm{pH}$ 's and as insoluble $\mathrm{Be}(\mathrm{OH})_{2}$ in-between. For example at 
172

a pH of $7,79 \%$ of $\mathrm{Be}(\mathrm{OH})_{2}$ is removed from the solution via filtration with a $0.45 \mu \mathrm{m}$ filter (Boschi and Willenbring, 2016). The solutions were placed on a roller table to allow constant mixing of the material and beryllium solution for 14 days.

\subsection{Solution Alteration}

After 14 days, control samples representing time ' 0 ' were measured to determine the amount of beryllium sorbed to each of the four materials. At this time, each of the berylliumsorbent mixtures, excluding the control samples, underwent chemical alteration through the addition of $0.25 \mathrm{~mL}$ of a $\mathrm{NaF}$ (Acros, New Jersey, USA), $\mathrm{NaCl}$ (Fisher Scientific), $\mathrm{HCl}$ (Fisher Scientific) and malonic acid (Fisher Scientific) solution. A small volume was used to ensure that the beryllium-sorbent solution was not diluted, thus affecting the system's equilibrium. Each of the chemical treatments was added to separate solutions so that a total of 18 solutions (for the 6 sampling events in triplicate) were prepared for each beryllium-sorbent mixture for each treatment. The final concentration of $\mathrm{NaF}, \mathrm{NaCl}$ and malonic acid in the beryllium-sorbent mixture represented that found in natural environments. Malonic acid was prepared so the final concentration was $5 \mathrm{mg} \mathrm{L}^{-1}$ (Harter and Naidu, 1995). The final concentration of $\mathrm{NaF}$ was 0.2 $\mathrm{mg} \mathrm{L}^{-1}$, representing the median dissolved fluoride concentration in freshwaters as reported in previous work showing strong correlation with dissolved beryllium concentrations (Vesely et al, 1989). The final concentration of $\mathrm{NaCl}$ was $2.2 \mathrm{~g} \mathrm{~L}^{-1}$ which falls within the range of brackish waters (NOAA, 2012). To test the effect of increased acidity on desorption, the $\mathrm{pH}$ was adjusted to a $\mathrm{pH}$ of 3 using $\mathrm{HCl}$. Considering the addition of malonic acid reduced the solution $\mathrm{pH}$ to 4 , we chose an even lower $\mathrm{pH}$ to simulate an acidic environment. 


\subsection{Sampling and Analysis}

At each time interval the solutions were filtered using a $0.45 \mu \mathrm{m}$ filter (Pall Life Sciences, Port Washington, NY, USA) to separate the amount of beryllium in solution from the amount of sorbed beryllium. The $\mathrm{pH}$ was monitored throughout the duration of the experiment and before each sampling event to ensure that the $\mathrm{pH}$ did not exceed 6 . The filtered solutions were analyzed using an inductively coupled plasma optical emission spectrophotometer (ICPOES) (Spectro, Mahwah, NJ, USA) to determine the concentration of unsorbed beryllium in solution.

To determine the amount of desorbed beryllium, we first measured the amount of beryllium sorbed by each material in the control solutions. We then calculated the difference in the concentration of beryllium in the chemically altered solution to that of the control solution at the same time interval to determine the amount of desorbed beryllium. The amount of desorbed beryllium was divided by the original sorbed amount in the control solution to determine the percent desorption that occurred due to the chemical treatment. In some instances, the chemical alteration caused increased sorption to the material. This was reported as a 'negative' percent desorption as shown in the following figures.

\section{$3 \quad$ Results and Discussion}

\subsection{Increase in Solution Ionic Strength}

By changing the ionic strength of the solution so that the final concentration of $\mathrm{NaCl}$ was $2.2 \mathrm{~g} \mathrm{~L}^{-1}$, we observe different responses between both mineral and organic compounds (Figure 1). In order to gauge the change in beryllium concentration, we calculated the overall percent desorption or increased sorption after the 7-day time period for each material (Table 1). The 
219 addition of $\mathrm{NaCl}$ caused sulfonate and montmorillonite to desorb $8.4 \%$ and $32 \%$, respectively, of

220 the original amount of sorbed beryllium after 7 days (Figure 1, Table 1). Conversely, it caused

221 illite and phosphonate to sorb additional amounts of beryllium by $96 \%$ and $17 \%$ of what was

222 originally sorbed, respectively.

223

224

225

226

227
Table 1: Percent desorption or increased sorption for each sorbent material 7 days after the addition of $\mathrm{HCl}$, Malonic Acid, $\mathrm{NaCl}$ and $\mathrm{NaF}$

\begin{tabular}{ccccccccc}
\hline & HCl & \multicolumn{2}{c}{$\begin{array}{c}\text { Malonic } \\
\text { Acid }\end{array}$} & NaCl & \multicolumn{2}{c}{ NaF } \\
\hline & $\% D$ & $\% S$ & $\% D$ & $\% S$ & $\% D$ & $\% S$ & $\% D$ & $\% S$ \\
Illite & 97 & 0 & 0 & 0.6 & 0 & 96 & 0 & 77 \\
Mont. & 75 & 0 & 46 & 0 & 32 & 0 & 0 & 0 \\
Sulfonate & 0 & 0 & 0.2 & 0 & 8.4 & 0 & 0 & 0 \\
Phosphonate & 0 & 44 & 1.4 & 0 & 0 & 17 & 0 & 2.1 \\
\hline
\end{tabular}

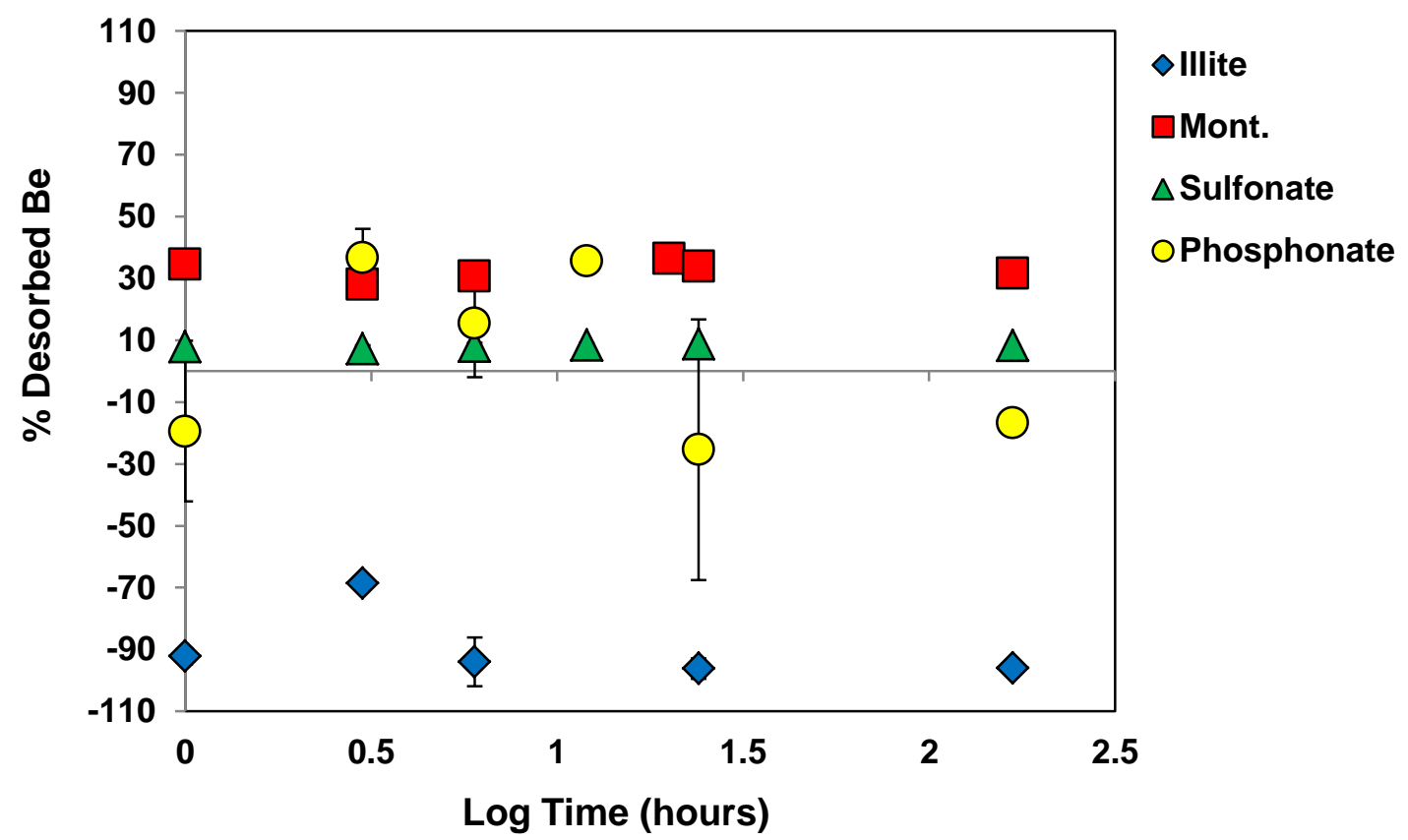

Figure 1: Percent desorbed beryllium from each sorbent material as a function of time after the addition of $\mathrm{NaCl}$ to produce a final concentration of $2.2 \mathrm{~g} \mathrm{~L}^{-1}$. Negative desorption means the material actually sorbed more beryllium as a result of the addition of $\mathrm{NaCl}$. 
The change in the ionic strength of the solution can affect both the behavior of the

beryllium and the behavior of the sorbent. For montmorillonite and, to a lesser extent, sulfonate, the increased concentration of competing ions for sorption sites lead to the displacement of beryllium by sodium cations. The difference in the magnitude of desorption relates to the nature of the beryllium-ligand complex formed by either the hydroxyl groups on the surface of montmorillonite particles or the sulfonate group of the toluene sulfonic acid compound. As shown in Boschi and Willenbring 2016, sulfonate is able to form stronger interactions with beryllium compared to the various organic ligands studied. Previously reported stability constants, a metric for metal-ligand strength, indicate that among organic and inorganic ligands, sulfur oxides are able to form strong interactions with beryllium (Alderighi et al, 2000). Therefore it is less thermodynamically favorable to disrupt a sulfonate-beryllium complex. Despite having a large surface area containing negatively charged hydroxyl groups, the significant amount of beryllium desorption from montmorillonite can infer two possible scenarios relating to complexation type. If complexation is dominated by inner sphere processes by which beryllium directly interacts with hydroxyl groups on mineral edge sites, then we might assume that beryllium is being complexed by a single hydroxyl group given the reversibility of the reaction as shown in Equation 1 where $\mathrm{SOH}$ represents a surface hydroxyl group, $\mathrm{M}^{2+}$ represents a divalent metal cation such as $\mathrm{Be}^{2+}$ and $\mathrm{SOM}^{+}$represents the metal-hydroxyl complex. However, we are aware from previous work that few monodentate ligands are able to compete with hydrolysis for beryllium complexation (Harter and Naidu, 1995). Additionally, reported stability constant values $\left(\log \mathrm{K}_{1}\right)$ for bidentate, dihydroxy containing ligands are as high as 16.2, indicating they form very stable complexes with beryllium and would not be as susceptible to desorption under the given conditions (Alderighi et al, 2000). Therefore, it seems 
less likely that beryllium would be directly complexed by a single or multiple hydroxyl groups on the surface of montmorillonite.

Conversely, it may be more likely that beryllium is retained through outer sphere complexation which involves the indirect sorption of beryllium to a surface by means of water molecules (Equation 2). Water molecules are electrostatically held to the surface while also hydrating beryllium cations. It is also generally accepted that outer sphere complexation occurs primarily on interlayer surfaces (Poinssot and Geckeis, 2012). Previous studies have shown that outer sphere complexation dominates when the ionic strength of the solution influences the amount of sorption unlike inner sphere complexation which is considered less susceptible to cation exchange (Sparks, 2003). This effect was investigated by Hayes and Leckie who used a modified version of the Triple Layer Model (TLM) to indirectly characterize the nature of metalligand complexation. The TLM is a surface complexation model that defines three separate electrical layers, the distribution of ions amongst these layers, as well as the surface charge and potential between planes (Figure 2) (Hayes and Leckie, 1987). Hayes and Leckie modified the original TLM to include inner sphere metal complexation rather than previously assuming metals where only complexed through outer sphere processes. They determined which process dominates metal sorption by performing sorption isotherms under different ionic strengths and comparing the empirical data to modeled outcomes representing inner and outer sphere complexation. Metal complexation dominated by outer sphere processes, occurring at the $\beta$ plane, is affected by the ionic strength of the solution whereas inner sphere complexation, occurring at the $o$-plane, is not. Therefore the equation characterizing outer sphere complexation accounts for the concentration of background electrolyte whereas the equation representing inner sphere complexation does not, as shown in equations 3-6 (Hayes and Leckie, 1987). Here, $K$ 
represents the thermodynamic equilibrium constant for either inner sphere $\left(K_{I . S .}\right)$ or outer sphere

281 processes $\left(K_{\text {O.S. }}\right), F$ represents Faraday constant in $\mathrm{C} \mathrm{mol}^{-1}, \psi_{i}$ represents the potential in the $i$ th

282 surface plane in $\mathrm{V}, R$ represents the gas constant in $\mathrm{J} \mathrm{mol}^{-1} \mathrm{~K}^{-1}, \sigma_{d}$ is the charge of the bulk

283 solution that balances the surface charge also known as the dissociate charge, $C$ is the

284 concentration of 1:1 background electrolyte (e.g. $\mathrm{NaCl}), \varepsilon_{\mathrm{r}}$ represents dielectric constant of water 285 and $\varepsilon_{0}$ represents the permittivity of vacuum.

\section{Inner Sphere Complexation}

(Eq. 1) $\mathrm{SOH}+\mathrm{M}^{2+} \leftrightarrow S O M^{+}+H^{+}$

\section{Outer Sphere Complexation}

(Eq. 2) $\mathrm{SOH}+\mathrm{M}^{2+} \leftrightarrow S \mathrm{~S}^{-}-\mathrm{M}^{2+}+H^{+}$

\section{Equilibrium Expressions}

(Eq. 3) $K_{I . S .}=\frac{\left[S O M^{+}\right]\left[H^{+}\right]}{[S O H]\left[M^{2+}\right]} \exp \left[-F \varphi_{o} / R T\right]$

(Eq. 4) $K_{O . S .}=\frac{\left[S O^{-}-M^{2+}\right]\left[H^{+}\right]}{[S O H]\left[M^{2+}\right]} \exp \left[-F\left(\varphi_{o}-2 \varphi_{\beta}\right) / R T\right]$

(Eq. 5) $\varphi_{\beta}=\left(\frac{\sigma_{d}}{C_{2}}\right)+\varphi_{d}$

Outer sphere complexation is affected by the ionic strength of the solution because it affects the (Eq. 6) $\sigma_{d}=-\left(8 R T C \varepsilon_{o} \varepsilon_{r}\right)^{1 / 2} \sinh \left(\frac{F \varphi_{d}}{2 R T}\right)$ sorption is affected by the electrolyte concentration, complexation is dominated by outer sphere processes. Considering beryllium is able to desorb from montmorillonite due to changes in ionic strength, it may indicate that beryllium sorption is dominated by outer sphere complexation under our experimental conditions including a solution $\mathrm{pH}$ of 6. 


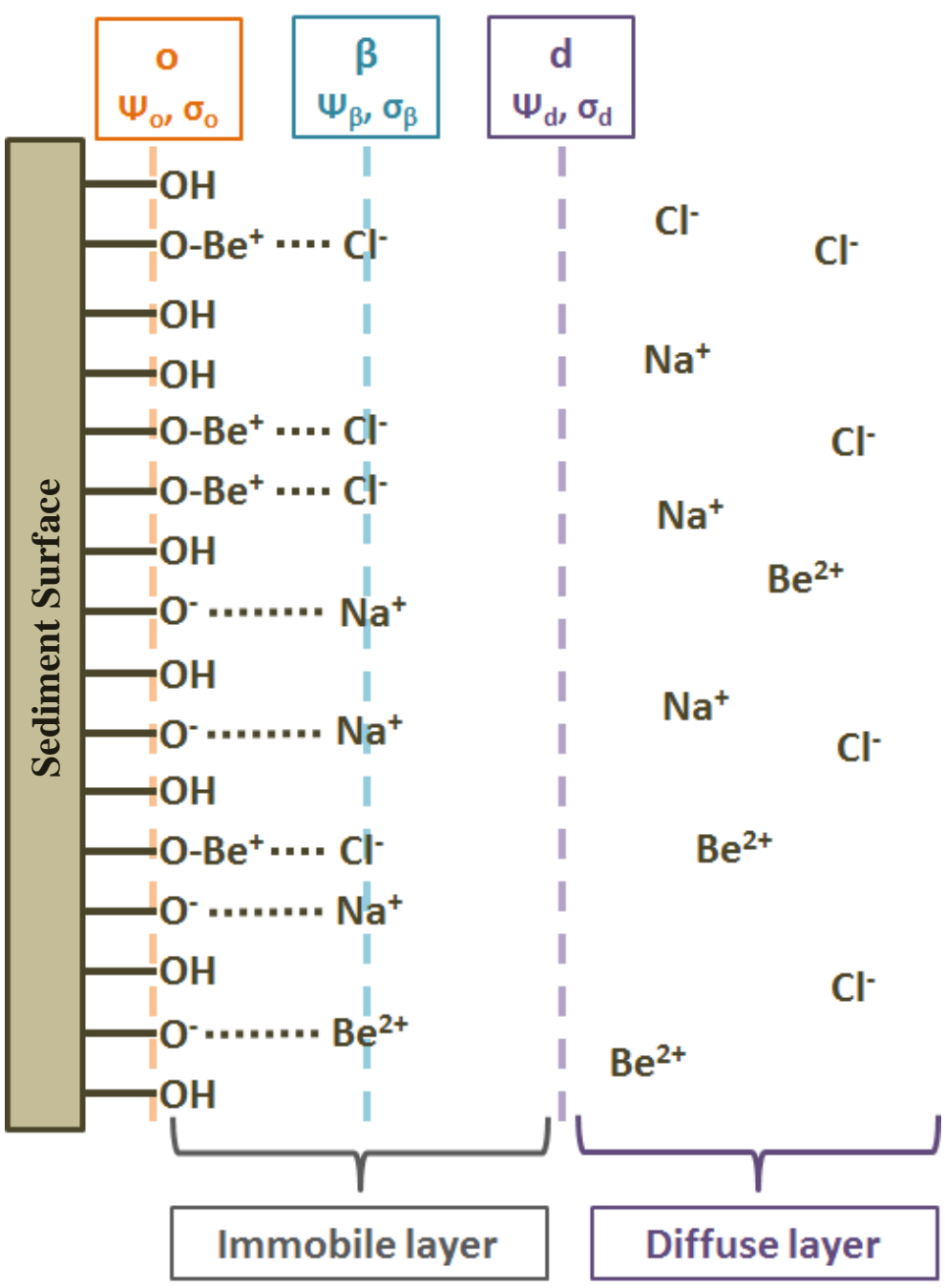

Figure 2: Triple Layer Model Schematic adapted from Hayes and Leckie, 1987 where $o, \beta$ and $d$ represent the three electrostatic planes with $\psi$ potential and a bulk solution charge of $\sigma$. Ions within the $o$ and $d$ boundaries have limited mobility while ions within the diffuse layer are more readily exchanged.

This hypothesis is further supported when we consider the strong association between beryllium and water molecules. Beryllium has a large charge to size ratio and is capable of strongly orienting water molecules around it forming polymeric hydrolysate products in an aqueous media (Walsh and Vidal, 2009). Of all divalent ions, beryllium is the most heavily hydrated and has the highest solvation energy (Martell and Hancock, 1996). The hydrolysis 
332 reaction of beryllium is described in Equations 7 and 8. It involves the initial hydration of

333 beryllium by four water molecules, covalently bound having tetrahedral geometry (Equation 7).

$$
\text { (Eq. 7) } \mathrm{Be}^{2+}+4 \mathrm{H}_{2} \mathrm{O} \leftrightarrow\left[\mathrm{Be}\left(\mathrm{H}_{2} \mathrm{O}\right)_{4}\right]^{2+}
$$

335 Beryllium is capable of strongly polarizing water molecules, orienting the negatively charged oxygen towards itself and causing strong repulsion amongst hydrogen atoms. This allows water molecules to more easily deprotonate with increasing $\mathrm{pH}$ resulting in a network of beryllium atoms bridged by hydroxyl groups (Equation 8). The bridging results in the initial formation of a trimer species (Figure 3).

(Eq. 8) $\left[\mathrm{Be}_{a}\left(\mathrm{H}_{2} \mathrm{O}\right)_{b}\right]^{2 a+}+c \mathrm{OH}^{-} \leftrightarrow\left[\mathrm{Be}_{a}\left(\mathrm{H}_{2} \mathrm{O}\right)_{b-c}(\mathrm{OH})_{c}\right]^{2 a-c}+c \mathrm{H}_{2} \mathrm{O}$

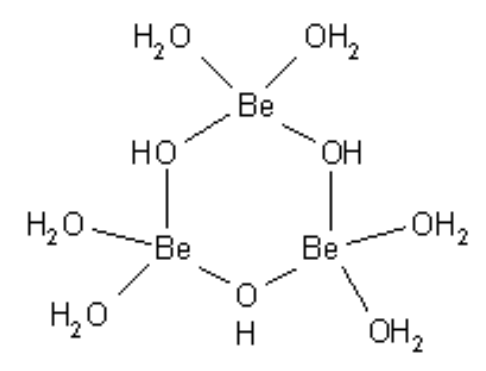

Figure 3: Structural formula for the trimeric beryllium hydrolysis product.

With increasing concentrations, these trimers gradually accumulate and form higher aggregates (Alderighi et al, 2000). These aggregates increase in size to become colloidal, eventually precipitating as insoluble $\mathrm{Be}(\mathrm{OH})_{2}$ depending on the concentration of beryllium in solution (Mattock, 1954). The strong arrangement and preference of beryllium for water ligands may result in an increased preference for outer sphere complexation mechanisms in the absence of more thermodynamically preferred ligands. 

what we already understand regarding beryllium hydrolysis, we hypothesize that beryllium sorbed to montmorillonite is dominated by outer sphere processes. Typically, we would employ $\mathrm{x}$-ray absorption spectroscopy to characterize and confirm metal complexation type. Unfortunately, these techniques are limited for light weight elements like beryllium. Therefore techniques to confirm dominate complexation mechanisms for beryllium.

Unlike montmorillonite, changes to the ionic strength of the solution caused an increase in the sorption of beryllium by illite which could be the result of changes in the structure of illite. Illite is a 2:1 aluminosilicate clay that is characterized as an intermediate between mica and smectite clays (Sparks, 2003). It differs from true micas in that only $1 / 6$ versus $1 / 4$ of the silicon atoms are replaced with aluminum atoms in the tetrahedral layer (Rolfe et al, 1960). Illite interlayers are occupied and tightly held together almost entirely by potassium ions. However previous work has shown that the edge sites of illite are void of potassium ions due to chemical weathering and are susceptible to infiltration and subsequent expansion by other hydrated cations such as sodium, calcium and magnesium (Fuller et al, 2015). The increase in the interlayer spacing of illite due to cation exchange and has been well documented (Smith, 1967). With the addition of sodium in attempts to increase the ionic strength of the solution, the subsequent lattice expansion would allow beryllium atoms to diffuse further into the interlayers thus enhancing its sorption potential relative to the amount initially sorbed. The exchange of cations at edge sites can also cause them to collapse, physically enveloping the metal and preventing it from desorbing back into solution. Increased sorption and resistance to desorption may suggest that beryllium is more physically protected by occupying the collapsed frayed edges of illite 
upon exchange with other interlayer cations as is observed with other metals like cesium (Fuller et al, 2015). Illites' planar surfaces are otherwise tightly held by potassium ions and less accessible relative to the hydrated interlayers of montmorillonite, thus frayed edge sites may be more readily populated. This mechanism would help to explain beryllium's physical protection and thus resistance to exchange with the solution over time. Further work involving the use of transmission electron microscopy will be employed to better understand the behavior of illite including the formation of collapsed edges in the presence of beryllium under various environmental conditions.

Similarly to illite, the fluctuation in beryllium sorption by phosphonate may be a result of the effect of ionic strength on the behavior of octadecylphosphonic acid itself. Although increasing the ionic strength of the solution initiated beryllium desorption from phosphonate, after 7 days equilibrium is established resulting in a net increase of beryllium sorption.

Octadecylphosphonic acid contains a hydrophilic, polar functional group with a large, hydrophobic hydrocarbon tail, which allows it to function as a surfactant. Thus, it is strongly affected by changes in ionic strength. Increasing the concentration of ions in solution dampens repulsions between polar, phosphonate head groups resulting in the formation of globular aggregates of individual molecules (Palladino and Ragone, 2011). Dissolved organic matter is also amphiphilic in nature and previous work has shown that its macromolecular structure is capable of forming aggregates in response to changes in solution chemistry including $\mathrm{pH}$ and ionic concentration (Ghosh and Schnitzer, 1980; Piccolo, 2001). These structural changes may affect the accessibility of the phosphonate groups, or other polar functionalities in the case of natural organic matter, therefore explaining fluctuations in the concentration of complexed beryllium over time. 
401

402

403

404

405

406

407

408

409

410

411

412

413

414

415

416

417

418

419

\subsection{Reduction in Solution $p H$}

There is a marked difference in the response between the minerals and organic compound with changes in solution $\mathrm{pH}$. The decrease in $\mathrm{pH}$ caused little to no desorption among the organic compounds. It actually caused an increase in the amount of beryllium to be sorbed by phosphonate after 7 days by $44 \%$ (Figure 4) (Table 1). Beryllium desorbed more easily from the minerals tested, with $75 \%$ and $97 \%$ of beryllium removal from montmorillonite and illite, respectively.

The reduction in $\mathrm{pH}$ did not desorb beryllium from sulfonate as its $\mathrm{pKa},-2.8$ for toluene sulfonic acid, is much lower than the $\mathrm{pH}$ of the solution. Therefore, it remained deprotonated and able to complex beryllium preventing desorption. For phosphonate, we observed that it continues to complex beryllium over time and sorbs $44 \%$ more beryllium than what was originally complexed. Longer equilibration times were required for beryllium complexation by phosphonate as previously reported in Boschi and Willenbring, 2016. Similar to changes in the ionic strength, the reduction in $\mathrm{pH}$ may not only affect protonation of polar functional groups but

17 it may also affect the aggregate behavior of octadecylphosphonic acid and thus the rate at which beryllium is complexed. 


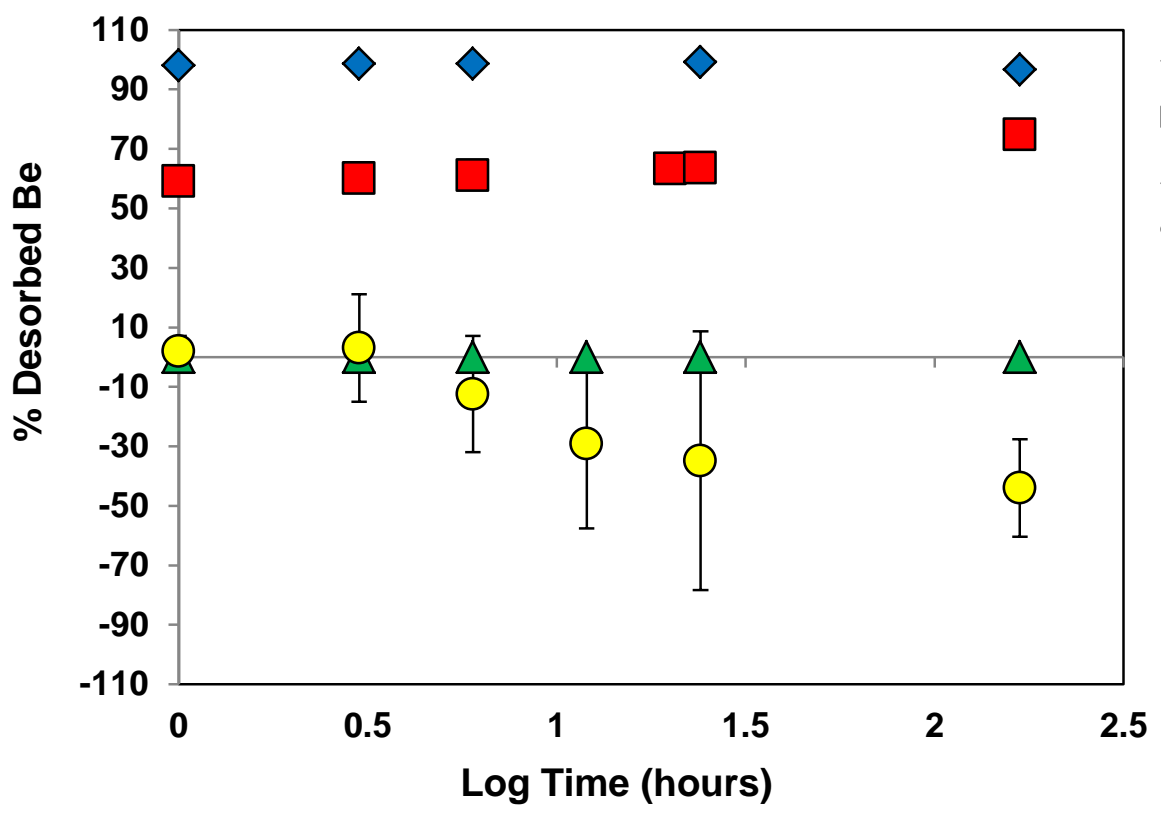

$\diamond$ Illite

$\square$ Mont.

$\triangle$ Sulfonate

OPhosphonate

Figure 4: Percent desorbed beryllium from each sorbent material as a function of time after the solution $\mathrm{pH}$ was lowered to 3 . Negative desorption means the material actually sorbed more beryllium as a result of the reduction in $\mathrm{pH}$.

$$
\text { attributed to the expected reduction in surface charge from increased protonation of the }
$$

negatively charged surface sites. The point of zero charge, pzc, or the $\mathrm{pH}$ at which the surface

charge of a mineral is equal to zero has been previously established as 2.5 and 3.2 for

montmorillonite and illite, respectively. Therefore by adjusting the $\mathrm{pH}$ to 3 , we observed greater amounts of desorption from illite. Montmorillonite has a greater pzc and it is able to maintain a more negatively charged surface at even lower $\mathrm{pH}$ 's, which resulted in relatively smaller amounts of desorption compared to illite.

\subsection{Addition of Organic Acid}

Similarly to the reduction in $\mathrm{pH}$, malonic acid caused negligible desorption of beryllium 
449 from the organic ligands after 7 days (Figure 5, Table 1). Malonate is able to chelate beryllium

450 and gains additional stability through the formation of the desired 6 member ring (Alderighi et al,

451 2000). However, stability constants previously determined for phosphonate- and sulfonate-

452 beryllium complexes are greater than that of malonate helping to explain the small amount of

453 desorbed beryllium. Additionally, the reduction in $\mathrm{pH}$ due to the addition of malonic acid did

454 not exceed the $\mathrm{pKa}$ of either ligand leaving them both predominantly deprotonated and available

455 for complexing beryllium.

The potential for beryllium desorption from organic ligands upon addition of a LMWOA will depend on the chemical properties and composition of the sorbed versus dissolved organic matter fractions in a given system. For example, in addition to phosphonate and sulfonate, other organic ligands associated with organic matter including aromatic dihydroxyl, hydroxycarboxylate and biscarboxylic functionalities similar to what is found in lignin, are also 461 able to form strong interactions with beryllium having stability constants ( $\log \mathrm{K}_{1}$ values)

462

463

464

465

466

467

468 469 470 471 exceeding 12 (Alderighi et al, 2000). Conversely, soluble, LMWOA most commonly abundant in soils including acetic, citric, formic, oxalic, malonic, malic and succinic acids have stability constants lower than 6 (Table 2) (Alderighi et al, 2000). These types of LMWOA would not be able to compete for beryllium complexation with the aforementioned ligands. Therefore, the type of ligands comprising the dissolved organic matter fraction will influence the potential for beryllium desorption from the sorbed organic fraction. The types of ligands found in either fraction will differ depending on many factors making it difficult to predict the potential for beryllium desorption unless both are sufficiently characterized. 


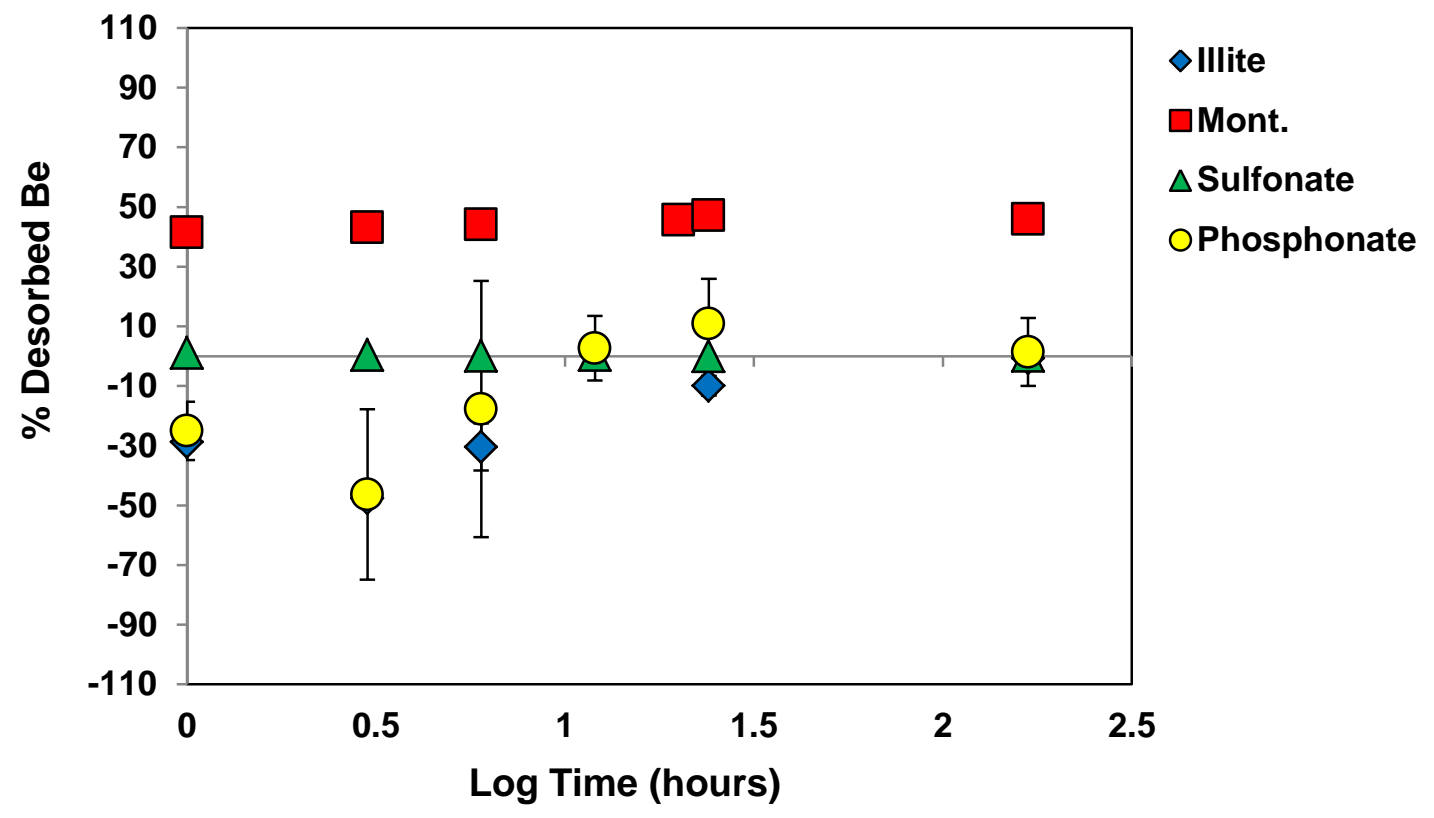

Figure 5: Percent desorbed beryllium from each sorbent material as a function of time after the addition of malonic acid to produce a final concentration of $5 \mathrm{mg} \mathrm{L}^{-1}$. Negative desorption means the material actually sorbed more beryllium as a result of the addition of malonic acid.

Table 2: Stability constants associated with low molecular weight organic acids most commonly identified in soils

\begin{tabular}{lc}
\hline & Log $\mathbf{K}_{\mathbf{1}}$ \\
\hline Malonic & 5.73 \\
Oxalic & 4.87 \\
Succinic & 4.69 \\
Maleic & 4.33 \\
Fumaric & 4.33 \\
Citric & 4.31 \\
Malic & 2.49 \\
Tartaric & 1.69 \\
Acetic & 1.62 \\
Propionic & 0.30 \\
Formic & 0.15 \\
\hline
\end{tabular}


Similar to the other treatments, the mineral fraction was more susceptible to beryllium mobilization. However, there was a difference in the response of beryllium desorption amongst montmorillonite and illite. The addition of malonic acid resulted in desorption of $46 \%$ of the original amount of beryllium sorbed by montmorillonite after 7 days. Conversely, it caused an initial increase in beryllium sorption by illite which was then released over time, resulting in a net zero desorption. Although illite has a higher pzc compared to montmorillonite and is therefore more sensitive to a reduction in solution $\mathrm{pH}$, the addition of malonic acid caused a greater amount of desorption from montmorillonite than from illite. Therefore we can again hypothesize that beryllium sorbed onto the surface of montmorillonite and illite is controlled by different mechanisms.

The lack of desorption observed from illite helps support our hypothesis that the majority of beryllium sorption occurs at edge sites and thus inner sphere mechanisms dominate beryllium complexation by illite. As previously discussed, access to the interlayer spacing of illite is restricted due to the abundance of tightly held potassium ions. This limits beryllium sorption to exterior basal surfaces or edge sites. The resistance to desorption upon addition of an organic complexing agent suggests inner sphere complexation may be the dominant mechanism thus supporting the occurrence of sorption at edge sites. Although we do observe desorption of beryllium from illite when we reduced the $\mathrm{pH}$ to 3 , the resultant $\mathrm{pH}$ was equivalent to the pzc of illite and thus we would expect to see significant removal of beryllium. Conversely, the addition of malonic acid only reduced the $\mathrm{pH}$ to 4 . Unlike planar sites which maintain a constant delocalization of negative charge among the basal oxygen atoms due to isomorphic substitution within the tetrahedral layer, protonation of edge hydroxyl groups are dependent on $\mathrm{pH}$ (Strawn 
and Sparks, 1999). Therefore sorption reversibility can occur but is most favorable at $\mathrm{pHs}$ similar to the pzc.

Unlike illite, the availability of interlayer spacing relative to the edge sites in montmorillonite combined with the observed reversibility of beryllium sorption, suggests that beryllium retention is dominated by outer sphere complexation on basal surfaces of montmorillonite. This is supported by other work that reported outer sphere complexation was most common on interlayer sites of montmorillonite at lower $\mathrm{pH}$ 's like those experienced from the addition of malonic acid reducing the solution pH to 4 (Gu et al, 2010; Strawn and Sparks, 1999). Therefore although montmorillonite may have greater surface area due to the accessibility of interlayer binding sites, outer sphere complexation processes appear to dominate in these regions creating weaker associations with beryllium. Again, the dominate complexation mechanism for either mineral would have to be confirmed through additional sorption experiments and modeling techniques.

\subsection{Addition of Fluoride (NaF)}

The addition of sodium fluoride caused increased sorption among illite and slight increase in sorption among montmorillonite but did not have any effect on the beryllium complexed by sulfonate (Figure 6) (Table 1). Although initially $38 \%$ of the total sorbed beryllium was able to desorb from phosphonate, after seven days there was a net zero desorption. The increased absorption for illite may again be explained by its sensitivity to changes in sodium concentrations, albeit small, helping to increase the interlayer spacing via ion substitution.

However overall, increased amounts of fluoride do not appear to promote beryllium desorption from either organic ligands or minerals. 


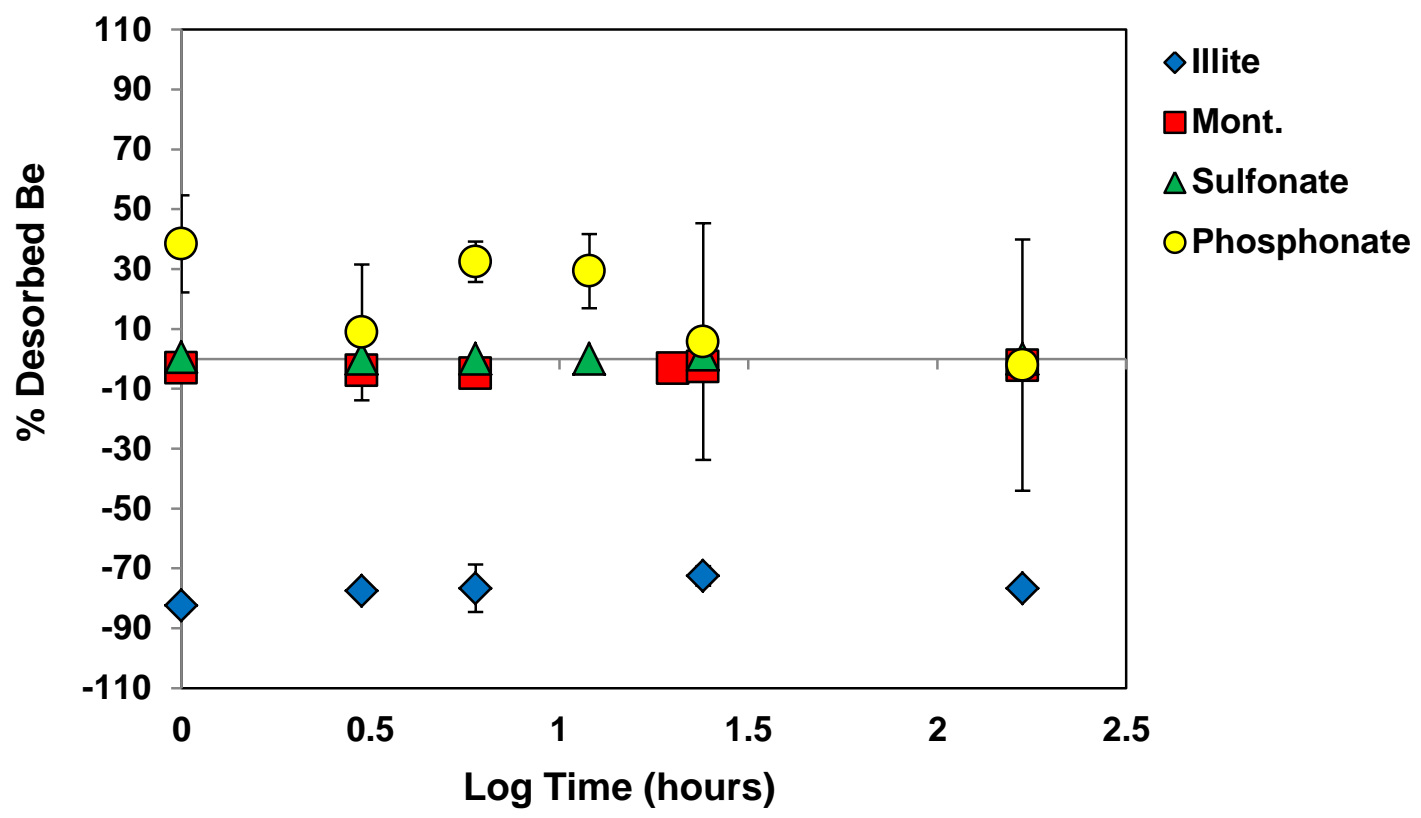

Figure 6: Percent desorbed beryllium from each sorbent material as a function of time after the addition of $\mathrm{NaF}$ to produce a final concentration of $0.2 \mathrm{mg} \mathrm{L}^{-1}$. Negative desorption means the material actually sorbed more beryllium as a result of the addition of sodium fluoride.

\section{Conclusions}

Although previously believed that beryllium sorbed to the surfaces of sediment or organic matter was resistant to desorption, our results show that various processes can promote the exchange of beryllium between solid and dissolved phases. Of all four treatments, a decrease in $\mathrm{pH}$ caused the greatest amount of desorption which was only observed for the minerals studied; the organic ligands were unaffected by changes in $\mathrm{pH}$. Montmorillonite was more susceptible to beryllium desorption considering the addition of malonic acid removed $46 \%$ of beryllium from montmorillonite but did not affect illite. As such, it is hypothesized that outer sphere processes are more dominate for montmorillonite whereas inner sphere complexation and physical inclusion is more common with illite due to differences in their clay structure. Illite exhibited an enhanced sorption capacity in the presence of sodium which is believed to cause increased 
interlayer spacing allowing for greater amounts of beryllium to occupy these areas. Our future work will focus on confirming the dominant complexation type and the physical behavior of beryllium in the presence of these two minerals using additional sorption experiments and surface complexation modeling.

Because of beryllium's resistance to desorption in the presence of organic ligands relative to the mineral fraction, we conclude that certain organic ligands can play an important role relating to beryllium mobility in soil and aquatic environments. The organic ligands tested were less susceptible to chemical perturbations. This emphasizes the importance of organic matter, its chemical composition and response to changes in solution chemistry when making predictions regarding beryllium mobility.

\section{Acknowledgements}

Research reported in this publication was supported by the National Science Foundation CAREER grant to Jane Willenbring. It was also supported by the National Institute of Environmental Health Sciences (NIEHS) of the National Institutes of Health (NIH) under award number P42 ES023720 Penn Superfund Research Program Center Grant. The content is solely the responsibility of the authors and does not necessarily represent the official views of the NIH. We thank the University of Pennsylvania for providing the facilities and instrumentation necessary for this work as well as David Vann for his technical assistance. We also thank Alain Plante and Art Johnson for their support.

\section{References}

Alderighi, L.; P. Gans; S. Midollini; A. Vacca (2000) Aqueous solution chemistry of beryllium. Adv. Inorg. Chem., 50, 109-172. 
604

605

606

607

608

609

610

611

612

613

614

615

616

617

618

619

620

621

622

623

624

625

626

627

628

629

630

631

632

633

634

635

636

637

638

639

640

641

Boschi, V.; J. K. Willenbring (2016) The effect of pH, organic ligand chemistry and mineralogy on the sorption of beryllium over time. Environ. Chem., doi:10.1071:EN15107

Fuller, A. J.; S. Shaw; M. B. Ward; S. J. Haigh; J. F. W. Mosselmans; C. L. Peacock; S.

Stackhouse; A. J. Dent; D. Trivedi; I. T. Burke (2015) Cesium Incorporation and Retention in Illite Interlayers. Applied Clay Science, 108, 128-134.

Ghosh, K.; M. Schnitzer (1980) Macromolecular structures of humic substances. Soil Science, 129, 266-276.

Granger, D. E.; N. A. Lifton; J. K. Willenbring (2013) A cosmic trip: 25 years of cosmogenic nuclides in geology. Geol. Soc. Am. Bull., 125, 1379-1402. doi:10.1130/B30774.1

Gu, X.; L. J. Evans; S. J. Barabash (2010) Modeling the Adsorption of Cd (II), Cu (II), Ni (II), $\mathrm{Pb}$ (II) and $\mathrm{Zn}$ (II) onto Montmorillonite. Geochimica Et Cosmochimica Acta., 74, 5718-5728.

Harter, R. D; R. Naidu (1995) Role of Metal-Organic Complexation in Metal Sorption by Soils. Advances in Agronom., 55, 219-263.

Hayes, K. F.; J. O. Leckie (1987) Modeling Ionic Strength Effects on Cation Adsorption at Hydrous Oxide/solution Interfaces. J Colloid Interf Sci., 115, 564-572.

Krám, P.; J. Hruška; C. T. Driscoll (1998) Beryllium Chemistry in the Lysina Catchment, Czech Republic. Biochemical Investigations at Watershed, Landscape, and Regional Scales, 409-415.

Martell, A. E.; R. D. Hancock (1996) Metal Complexes in Aqueous Solutions. New York: Plenum.

Mattock, G. (1954) The Hydrolysis and Aggregation of the Beryllium Ion. J. Am. Chem. Soc., $76,4835-838$.

NOAA (2012) "Estuaries." NOAA's National Ocean Service Education, National Oceanic and Atmospheric Administration, July-Aug. 2012. Web. 04 Jan. 2016.

Palladino, P; R. Ragone (2011) Ionic Strength Effects on the Critical Micellar Concentration of Ionic and Nonionic Surfactants: The Binding Model. Langmuir, 27, 14065-14070.

Piccolo, A (2001) The Supramolecular Structure Of Humic Substances. Soil Science, 166, 810832.

Poinssot, C.; H. Geckeis (2012) Radionuclide Behaviour in the Natural Environment: Science, Implications and Lessons for the Nuclear Industry: Chapter 8, 1st ed. Oxford: Woodhead Pub.

Rolfe, B. N.; R. F. Miller; I.S. McQueen (1960) Dispersion characteristics of montmorillonite, kaolinite and illite clays in waters of varying quality and their control with phosphate dispersants. United States Geological Survey Professional Paper, 334-G, 229-271. 
Qin, F.; X. Shan; B. Wei (2004) Effects of Low-molecular-weight Organic Acids and Residence Time on Desorption of $\mathrm{Cu}, \mathrm{Cd}$, and $\mathrm{Pb}$ from Soils. Chemosphere, 57, 253-263.

Smith, S.J. (1967) Susceptibility of interlayer potassium in illites to exchange. Ph.D. Diss. Iowa State University, Ames, IA. 1967 (Diss. Abstr. 67-08935).

Sparks, D. L. (2003) Environmental Soil Chemistry. Amsterdam: Academic Press.

Strawn, D. G.; D. L. Sparks (1999) The Use of XAFS to Distinguish between Inner- and OuterSphere Lead Adsorption Complexes on Montmorillonite. J Colloid Interf Sci., 216, 257-269.

Taylor, T.; M. Ding; D. Ehler; T. Foreman; J. Kaszuba; N. Sauer (2003) Beryllium in the environment: a review. J. Environ. Sci. Health.Journal of Environmental Science and Health, A38, 439-469. doi:10.1081/ESE-120016906

US DHHS (2002) Toxicological Profile for Beryllium (US Department of Health and Human Services, Public Health Service Agency for Toxic Substances and Disease Registry: Atlanta, GA, USA).

Vanhees, P.; J. Dahlen; U. Lundstrom; H. Boren; B. Allard (1999) Determination of Low Molecular Weight Organic Acids in Soil Solution by HPLC. Talanta, 48, 173-179.

Vesely, J.; P. Beneš; K. Ševčí (1989) Occurrence and Speciation of Beryllium in Acidified Freshwaters. Water Research, 23, 711-717.

Vesely, J.; S. A. Norton; P. Skrivan; V. Majer; P. Kram; T. Navratil; J. M. Kaste (2002) Environmental chemistry of beryllium. Rivers in Mineralogy and Geochemistry Rev. Mineral Geochem. 2002, 50, 291-3187. doi:10.2138/rmg.2002.50.7

Vranova, V.; K. Rejsek; P. Formanek (2013) Aliphatic, Cyclic, and Aromatic Organic Acids, Vitamins, and Carbohydrates in Soil: A Review. The Scientific World Journal, 2013, 1-15.

Wallbrink, P. J.; A. S. Murray (1996) Distribution and variability of 7Be in soils under different surface cover conditions and its potential for describing soil redistribution processes. Water Resour. Res., 32, 467-476. doi:10.1029/95WR02973

Walsh, K. A.; E. E. Vidal (2009) Beryllium Chemistry and Processing. Materials Park, OH: ASM International, 2009.

Willenbring, J. K.; F. von Blanckenburg (2010a) Meteoric cosmogenic beryllium-10 adsorbed to river sediment and soil: applications for Earth-surface dynamics. Earth Sci. Rev., 98, 105-122. doi:10.1016/j.earscirev.2009.10.008

Willenbring, J. K.; F. von Blanckenburg (2010b) Long-term stability of global erosion rates and weathering during late Cenozoic cooling. Nature 2010, 465, 211-214. doi:10.1038/nature09044 